\title{
Regulation of Growth in Avena Stem Segments by Gibberellic Acid and Kinetin
}

\author{
By \\ R. A. JONES and P. B. KAUFMAN \\ Department of Botany, University of Michigan, Ann Arbor, Michigan 48104 \\ (Received October 15, 1970)
}

\begin{abstract}
Kinetin at physiological concentrations causes significant reduction of $\mathrm{GA}_{3}$-promoted growth in excised Avena stem segments. Kinetin is therefore considered to be a gibberellinantagonist in this system. A Lineweaver-Burke plot reveals that kinetin acts non-competitively with $\mathrm{GA}_{3}$. The kinetin inhibition of $\mathrm{GA}_{3}$-promoted growth can be seen within 6 hours. It was found that soluble protein is markedly increased by kinetin in the tissue during the first 3 hours, thus preceding the inhibition of $\mathrm{GA}_{3}$-promoted growth by several hours. At the cellular level, kinetin negated the blocking effect of $\mathrm{GA}_{3}$ on cell division in the intercalary meristem portions of these segments. In fact, kinetin promotes both lateral and longitudinal cell divisions in intercalary meristem cells.
\end{abstract}

\section{Introduction}

The discovery of the stimulation of cell division in plant tissues by trace amounts of kinetin, 6-furfurylaminopurine (Miller et al. 1955), has resulted in a number of investigations on the effect of this and related compounds on growth physiology and metabolism in a variety of plant and animal systems (Gorton et al. 1957, Lettré and Endo 1956). Kinetin has been reported to have an inhibitory effect on the elongation of stem sections in several of these plant systems (De Ropp 1956). This inhibition is not reversed by $\mathrm{GA}_{3}$ (Brian and Hemming 1957). Although it has long been known that in some intact plant systems kinetin also inhibits $\mathrm{GA}_{3}$ induced stem elongation (Wittwer and Dedolph 1963), our knowledge of the nature and mechanism of this interaction is scanty. This can be attributed to the complex nature of the processes involved and to the relative insensitivity of the plant systems studied to either gibberellin or kinetin.

We have previously found that gibberellic acid $\left(\mathrm{GA}_{3}\right)$ markedly accelerates the rate of intercalary growth and cell lengthening in Avena internodes and in excised stem segments (Kaufman 1965, Kaufman 1967). In preliminary experiments we found that kinetin strikingly suppresses the growth promoting action of $\mathrm{GA}_{3}$ in darkincubated Avena internode segments. The following experiments were, therefore, carried out to analyze the mode of action of such a sensitive and antagonistic hormonal interaction. The results presented here indicate that a cytokinin such as kinetin could be of physiological significance in the hormonal control of intercalary growth in this system through its interaction with gibberellin-type hormones.

Abbreviation used: $\mathrm{IM}=$ intercalary meristem.

\section{Materials and Methods}

Plants of Avena sativa cv. Victory were grown in the light in a greenhouse with a mean night temperature of $22^{\circ} \mathrm{C}$ and a mean day temperature of $26.5^{\circ} \mathrm{C}$. At the time the plants were 40 days old, stem segments (IM segments) were excised from the bases of next-to-last internodes ( $\mathrm{p}-1$ internode). The $\mathrm{p}-1$ internodes in this case were 8 to $10 \mathrm{~mm}$ in length.

Isolation and preparation of the Avena IM segments essentially follows that cited in Kaufman et al. (1969) with the exception that twenty IM segments were supported in raised perforated plexiglass disks on filter paper in $5 \mathrm{~cm}$ Petri dishes, with the bases of the segments immersed in $2 \mathrm{ml}$ of treatment solution. The segments were surface-sterilized in 10 per cent "Clorox" (sodium hypochlorite) for two minutes, then thoroughly washed with 8-10 changes of distilled water. This treatment effectively prevents any microbial contamination in the incubation medium.

Two parallel series of treatments were run; one, where the control solution was distilled $\mathrm{H}_{2} \mathrm{O}$ and, the second, where the control solution was $0.1 M$ sucrose. IM seg- 

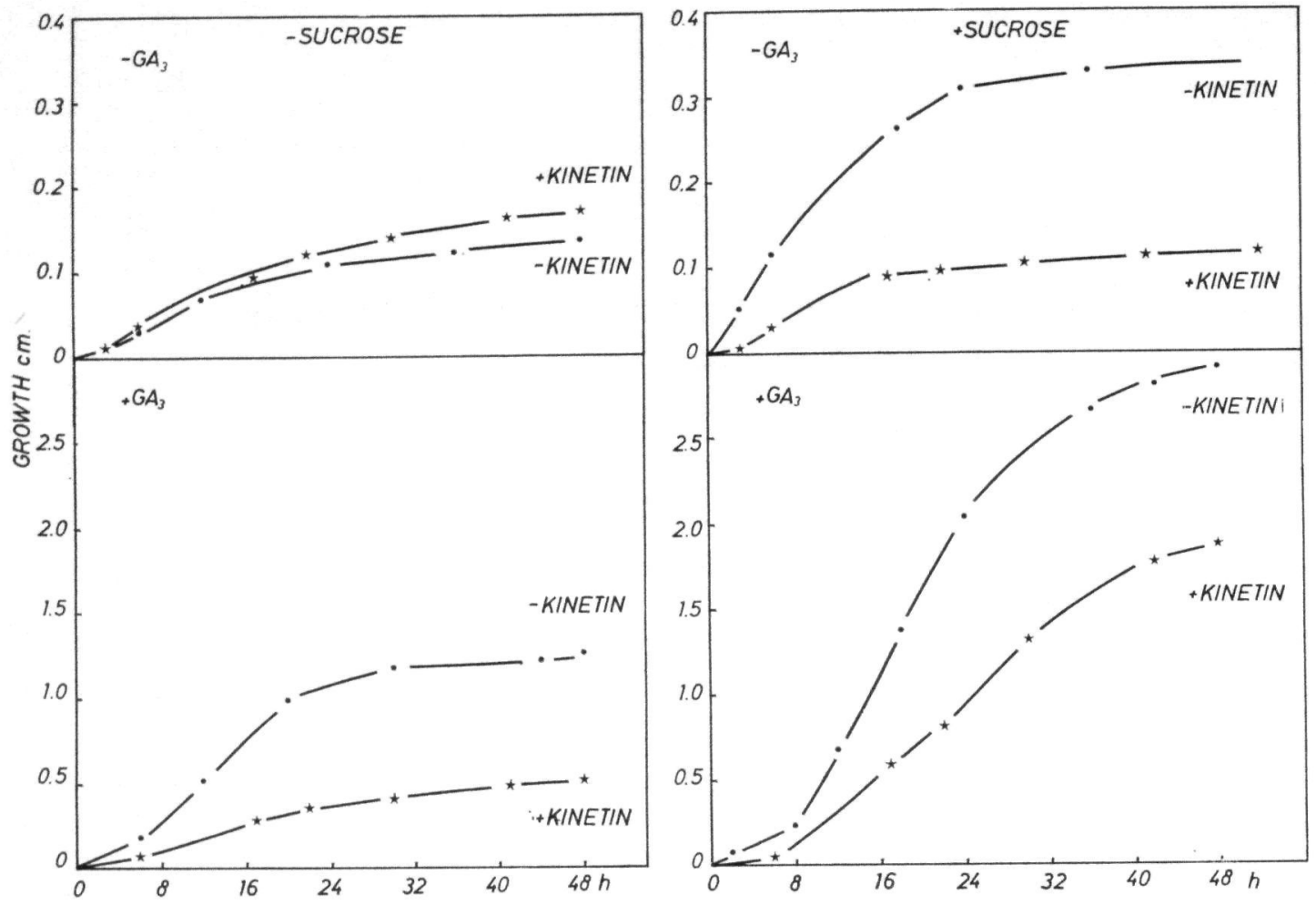

Figure 1. Time-course growth (in length) responses of Avena IM segments treated with $G A_{3}(1 \mu M)$ with and without kinetin $\left(10^{-4} M\right)$ in the absence and presence of $0.1 M$ sucrose.

ments were also placed in the control solutions containing kinetin (6-furfurylaminopurine) varying in concentration from $10^{-9} M$ to $10^{-4} M$ and/or gibberellic acid which was used at $10^{-6} M$. This concentration of $\mathrm{GA}_{3}$ evokes a nearly maximal growth response in these segments (Adams 1969). Treated segments were incubated at $23^{\circ} \mathrm{C}$ in the dark for periods up to 48 hours, during which time the net increase in IM segment length was measured at 3 to 12 hour intervals to the nearest 0.5 $\mathrm{mm}$ with a millimeter ruler.

For light microscopy studies, Avena IM segments were incubated as cited above and removed after 48 hours. The preparation of epidermal peels for cell size and number determinations was done according to procedures cited in Kaufman et al. (1969).

Soluble protein was extracted from frozen tissue (12 IM segments) in $4 \mathrm{ml}$ cold $5 \mathrm{mM}$ phosphate-citrate buffer $(\mathrm{pH} 5.0)$ and about $1.5 \mathrm{~g}$ sand in a porcelain mortar (70 $\mathrm{ml}$ capacity). This and all subsequent steps were carried out at $0-4^{\circ} \mathrm{C}$. The crude protein extract was then centrifuged at $1700 \times g$ for $10 \mathrm{~min}$ with an International clinical centrifuge, and the supernatant decanted off. The pellet was resuspended and extracted a second time. Soluble protein was determined according to the method of Lowry et al. (1951).

Gibberellic acid was obtained from Imperial Chemical Industries, Ltd., England; Kinetin (6-furfurylaminopurine) from Nutritional Biochemicals, Inc., and "Victory" oats from the Swedish Seed Association, Svalöf, Sweden.

\section{Experimental Results}

\section{Kinetics of growth response to kinetin}

The effects of $10^{-4} \mathrm{M}$ kinetin in the absence of sucrose on linear growth in IM segments cultured for 48 hours in the dark are shown in Figure 1. Comparison of the growth curves for kinetin $+\mathrm{H}_{2} \mathrm{O}$ and $\mathrm{H}_{2} \mathrm{O}$ alone shows that growth is closely parallel during the first 24 hours. After 24 hours there is a slight promotion of growth induced by the kinetin treatment. The curves in the diagram below also indicate that $\mathrm{GA}_{3}$ at $10^{-6} M$ causes a significant acceleration of growth. This increase in linear growth elicited by $\mathrm{GA}_{3}$ is markedly diminished by $10^{-4}$ $M$ kinetin. A lag in growth is seen as early as 6 hours. The maximum repression of growth occurs within 24 hours. These experiments show that kinetin almost completely negates $\mathrm{GA}_{3}$-accelerated exponential growth in these segments.

The effect of $10^{-4} M$ kinetin on the linear growth of Avena IM segments incubated for 48 hours in the dark in the presence of sucrose is shown in Figure 1 (right). In the absence of $\mathrm{GA}_{3}$, kinetin inhibits by 68 per cent the sucrose-promoted growth. This inhibition can be observed within the first 3 hours. Kinetin also clearly, and very early, inhibits the linear growth promoted by GA. In this case, a marked inhibition occurs during the lag phase of linear growth. No further growth suppression takes place after 24 hours. Comparison of growth in the presence and absence of exogenous sucrose shows that 


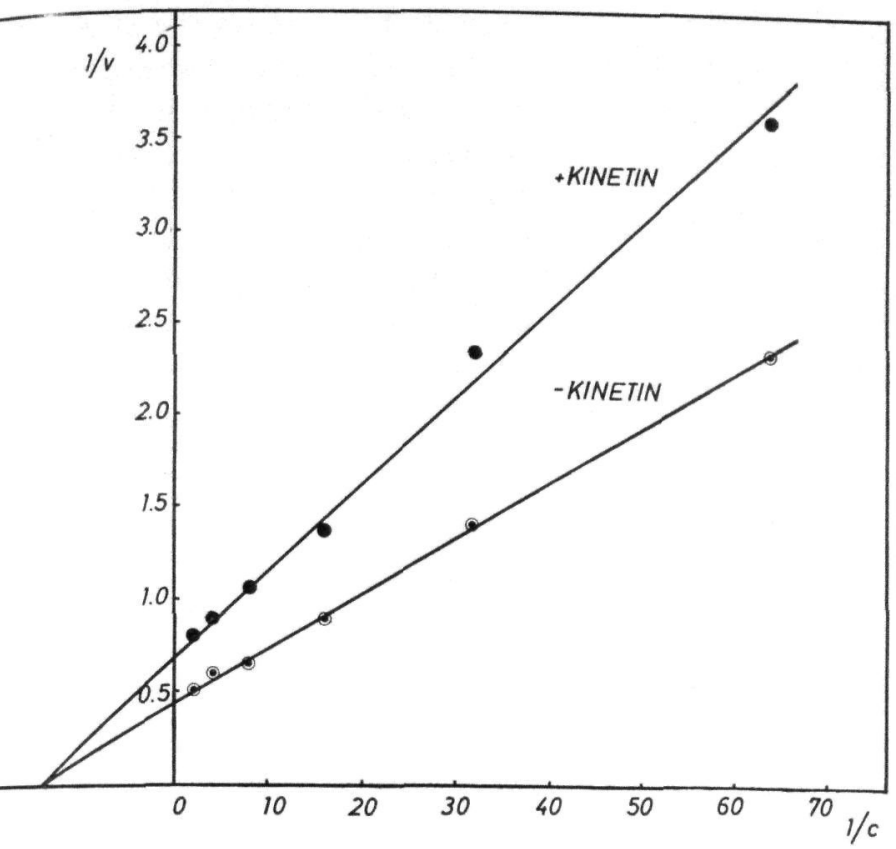

Figure 2. Lineweaver-Burke plot, showing the effect of an inbibitory concentration of kinetin $\left(10^{-4} M\right)$ on the linear growth rate of $G A_{3}$-treated Avena IM segments. $\mathrm{GA}_{3}$ was used in the range of 0.015 to $0.5 \mu M$.

kinetin drastically reduces sucrose-promoted growth, which is depressed to a level even lower than that of the $\mathrm{H}_{2} \mathrm{O}$ control. It is further evident that exogenous sucrose is partially able to relieve the inhibition of $\mathrm{GA}_{3}-$ promoted elongation elicited by kinetin (cf. the two bottom diagrams of Figure 1).

\section{Nature of the inbibition of $G A_{3}$-promoted growth by kinetin}

In further experiments, the nature of the inhibition of $\mathrm{GA}_{3}$-promoted growth by kinetin was studied by means of a Lineweaver-Burke plot. Figure 2 shows that kinetin is acting in a non-competitive fashion. These results suggest that kinetin may not be competing with $\mathrm{GA}_{3}$ at the same site, but rather, could be acting at another site(s) which results in interference of the action of $\mathrm{GA}_{3}$ on cell elongation in IM segments. This type of inhibition caused by kinetin is similar to that found between IAA and $\mathrm{GA}_{3}$ (Kaufman et al. 1969).

\section{Effects of varying kinetin concentrations on growth}

The first experiments tested the effects of kinetin on $\mathrm{GA}_{3}$-promoted growth in the absence of sucrose. Figure 1 (left bottom diagram) indicates a concentration of kinetin which causes pronounced suppression of $\mathrm{GA}_{3}$-promoted growth in IM segments. The amount of growth in the control averages $0.14 \pm 0.02 \mathrm{~cm}$ at 48 hours

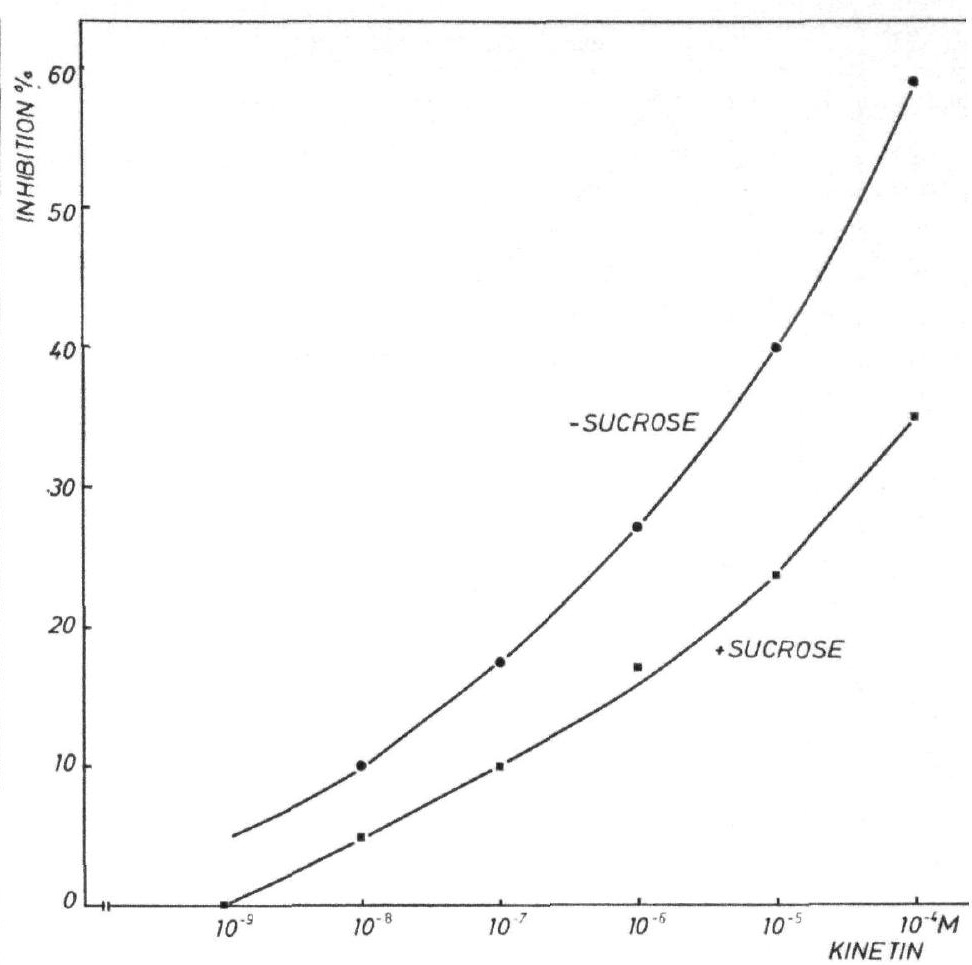

Figure 3. Comparison of per cent inhibition of GA3-promoted growth in Avena IM segments incubated in kinetin varying from $10^{-9}$ to $10^{-4} \mathrm{M}$.

(Figure 1, left top diagram). The growth of segments treated with $1 \mu M \mathrm{GA}_{3}$ is $1.28 \pm 0.04 \mathrm{~cm}$ at 48 hours. When $\mathrm{GA}_{3}$ at $1 \mu M$ is supplied with varying concentrations of kinetin, the growth response (Figure 3 ) indicates that kinetin suppresses $\mathrm{GA}_{3}$-promoted growth at concentrations as low as $10^{-9} \mathrm{M}$. The amount of growth suppression ranges from 5 per cent at $10^{-9} M$ to 58 per cent at $10^{-4} M$ kinetin. Clearly then kinetin is capable of suppressing $\mathrm{GA}_{3}$-enhanced growth in IM segments over a wide concentration range which is of physiological significance. Wittwer and Dedolph (1963) observed that kinetin at all physiologically active concentrations inhibits the growth rate of intact green plants, as evidenced by depressed stem elongation.

The second experiments tested the effect of kinetin on $\mathrm{GA}_{3}$-promoted growth in the presence of sucrose. The amount of growth in control segments in $0.1 M$ sucrose is $0.32 \pm 0.01 \mathrm{~cm}$ at 48 hours; the growth of segments treated with $0.1 M$ sucrose and $1 \mu M \mathrm{GA}_{3}$ is $2.92 \pm 0.06$ $\mathrm{cm}$ at 48 hours. When $\mathrm{GA}_{3}(1 \mu M)$ is used in the presence of varying concentrations of kinetin, the results indicate that kinetin suppresses $\mathrm{GA}_{3}$-promoted growth at kinetin concentrations as low as $10^{-8} M$ (Figure 3 ). The amount of suppression increases from 5 per cent at $10^{-8} M$ to 35 per cent at $10^{-4} M$ kinetin. No appreciable inhibition of $\mathrm{GA}_{3}$-promoted growth is caused by kinetin at $10^{-9} \mathrm{M}$. These data thus show that kinetin is indeed capable of suppressing $\mathrm{GA}_{3}$-enhanced growth 


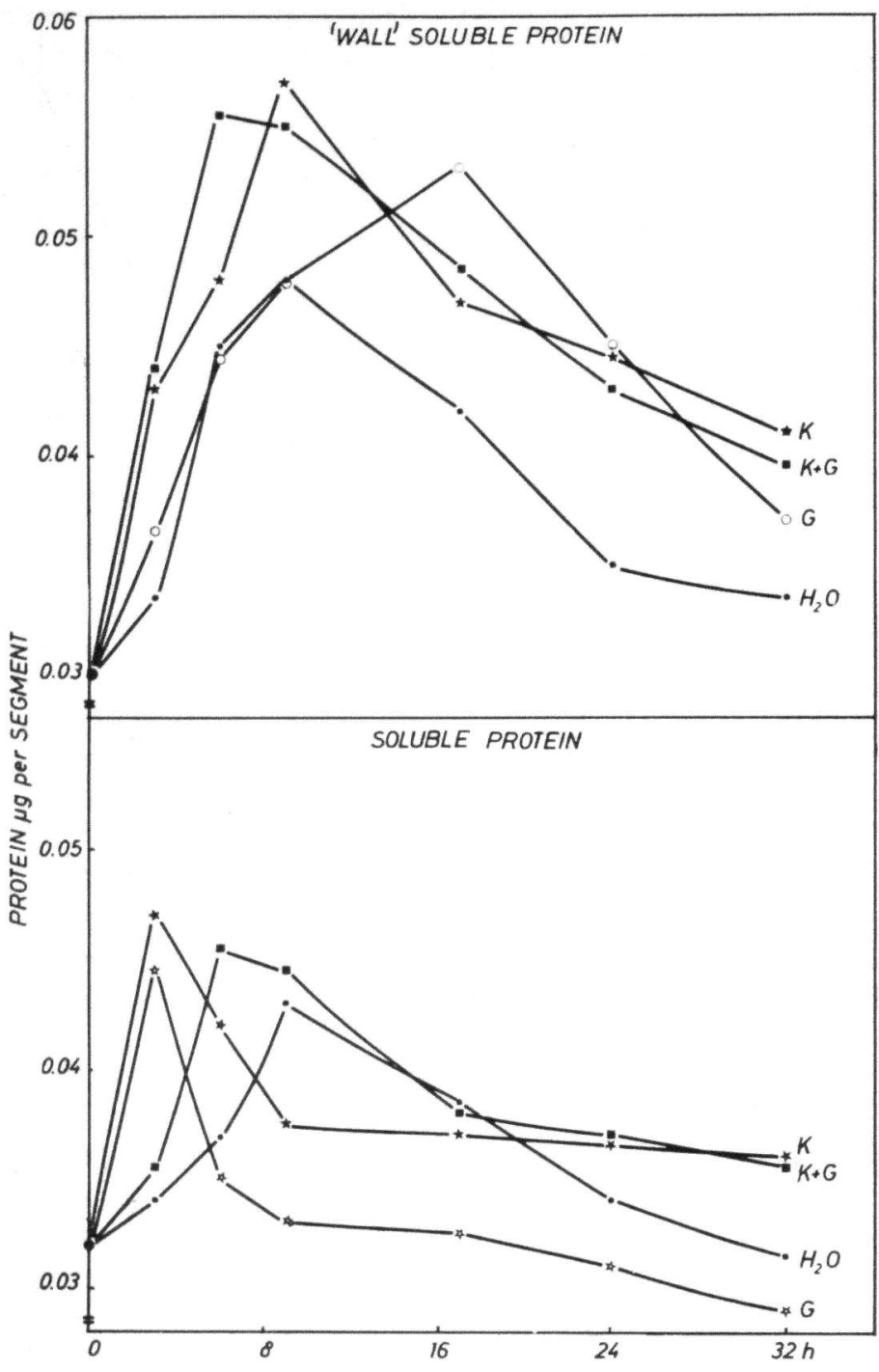

Figure 4. Time-course changes in soluble and "wall" protein in Avena IM segments treated with $\mathrm{H}_{2} \mathrm{O}$, kinetin at $10^{-4} \mathrm{M}$, $G A_{3}$ at $1 \mu M$, and kinetin plus $G A_{3}$ at same respective concentrations.

in Avena IM segments within the physiological range of $10^{-8} M$ to $10^{-4} M$ kinetin in the presence of exogenous substrate. Further, this suppression is much greater in a substrate-limited system, and it extends over a wider concentration range than is found when sucrose is included in the incubation medium. This suggests that kinetin may have a significant effect on carbohydrate metabolism.

\section{Analyses of the effects of kinetin on soluble protein levels}

The next part of this study was concerned with the question of the amount of time necessary for kinetin and $\mathrm{GA}_{3}$ to cause alterations in soluble protein pool size in Avena IM segments. Figure 4 illustrates the effects of kinetin at $10^{-4} M$ on the amount of soluble protein in supernatant fractions of segments incubated in the dark for 32 hours. The curves indicate that (a) in control segments, the soluble protein increases during the inicial growth period, reaches a maximum at about 9 hours, and slowly declines during the next 21 hours; (b) gibberellin rapidly increases the pool of soluble protein to a peak at 3 hours, which is slightly above that in control segments; it then rapidly declines below the initial level and 10 per cent below that in control segments at 32 hours; (c) kinetin treatment causes a 25 per cent increase in protein level over that of control segments, with this maximum level reached in 3 hours; it then declines slowly such that kinetin maintains higher levels of protein for a longer period of time; (d) the protein pool size in kinetin $+\mathrm{GA}_{3}$-treated segments rises slowly during the first 3 hours, then increases rapidly, reaching a maximum level by 6 hours. Similar to kinetin alone, the protein level falls off gradually, maintaining a significantly higher protein pool size during the last 16 hours (16 to 32 hours) of incubation, as compared with that for water control.

The effects of similar treatments on soluble protein levels in "wall" fractions of the tissue are also shown in Figure 4. The curves indicate that (a) protein in this "wall" fraction gradually increases in control segments, reaching a maximum by 9 hours, and slowly declining afterwards; (b) the "wall" protein level in $\mathrm{GA}_{3}$-treated segments rises parallel to that in control segments during the first 9 hours of growth, then continues to increase gradually up to 17 hours and finally falls rapidly during the remainder of the growth period; (c) in kinetintreated segments there is a rapid increase in "wall" protein over that in control segments (ca. a 30 per cent increase), reaching a maximum in 9 hours and then slowly falling off, thus maintaining higher protein levels in the "wall" fraction over a longer period of time; (d) the protein pool size in kinetin $+\mathrm{GA}_{3}$-treated segments rises parallel to kinetin-treated segments for the first 3 hours, reaching a maximum level in 6 hours, and then falling off parallel to that for kinetin-treated segments.

\section{Cellular basis for kinetin action on growth}

It was previously shown that the primary basis for $\mathrm{GA}_{3}$-promoted linear growth of Avena IM stem segments is accelerated cell lengthening (Kaufman 1965). This is also evident for epidermal cells in the IM segments treated here (Figure 5, middle left). The greatest promotion (up to 296 per cent) by $\mathrm{GA}_{3}\left(10^{-6} \mathrm{M}\right)$ on cell lengthening occurs in immature cells in the IM and just above it. Less promotion (up to 270 per cent) is seen in more mature cells well above the IM. The long epidermal cells of $\mathrm{GA}_{3}$-treated segments attain an average length approximately three times as long as that in con- 
overrides kinetin in its effect on cell lengthening and lateral expansion of cells well above the IM. These older cells are much longer than comparable cells in untreated internodes.

\section{Discussion}

The present studies have shown that in Avena IM segments, kinetin slightly promotes elongation growth only in the absence of exogenously supplied substrate. The greatest promotion (151 per cent) was found at the highest kinetin concentration tested, $10^{-4} \mathrm{M}$. This promotion of growth occurs at levels as low as $10^{-9} M$ kinetin (114 per cent). In contrast, these segments are much more sensitive to gibberellin. $\mathrm{GA}_{3}$ promotes linear growth in IM segments as much as 820 per cent at $10^{-6} \mathrm{M}$; this growth promotion occurs at concentrations as low as $10^{-8} M \mathrm{GA}_{3}$. Kinetin, at physiological concentrations, when used in combination with $\mathrm{GA}_{3}\left(10^{-6}\right.$ $M$ ), suppresses $\mathrm{GA}_{3}$-promoted growth. The extent of this suppression is as much as 58 per cent at $10^{-4} M$ and 5 per cent at $10^{-9} M$ kinetin (Figure 3). In several other plant systems, namely sunflower hypocotyls (de Ropp 1956) and pea stem segments (Brian and Hemming 1957), exogenous kinetin, when supplied with gibberellin in physiological concentrations, has the effect of suppressing gibberellin-promoted longitudinal growth. Recently, another cytokinin, benzyladenine, was reported to antagonize gibberellin-induced stimulation of Begonia petiole extension (Heide 1969).

At the cellular level, the site of action of kinetin in control of growth in Avena internodes is quite specific. Results here show that kinetin significantly promotes cell division activity within the IM but not above it. Kinetin not only increases linear growth by enhancing the number of transverse divisions; it also significantly increases the diameter of internodes in the IM locus by altering the plane of cell division at this site. This intensification of cell division activity is in direct contrast to a number of other systems where kinetin has been shown to stimulate cell expansion as in mature storage tissue (Kuraishi 1959, Kursanov 1969). However, it is more analogous with other meristematic systems, such as tissue cultures, where cytokinin clearly promotes cell division (Murashige and Skoog 1962, Miller 1968, Fox and Chen 1968). The main difference is that these tissues usually require exogenous auxin to obtain the cell division induction by kinetin.

In previous experiments, we have shown that $\mathrm{GA}_{3}$ markedly accelerates linear extension in Avena IM segments (Kaufman 1967, Kaufman et al. 1968, Adams, Ph.D. Diss. Univ. Mich. Ann Arbor, 1969). At the same time $\mathrm{GA}_{3}$ causes a cessation of all cell division activity within the intercalary meristem (Kaufman 1965). The present results indicate that kinetin may have marked effects on gibberellin-promoted growth at the cellular level in these segments. First, it reverses the $\mathrm{GA}_{3}$ inhibition of cell division activity (both lateral and transverse divisions) at this locus. This regulation of cell division activity in the IM occurs at physiological levels of kinetin $\left(10^{-9} M\right.$ to $\left.10^{-4} M\right)$. Second, it clearly brakes the action of $\mathrm{GA}_{3}$ on cell elongation in this same IM locus as well as above it (Figure 5). From these results one cannot escape the conclusion that kinetin, as an antagonist of $\mathrm{GA}_{3}$-induced elongation, appears to be essential for the control of normal cell division and lengthening during intercalary growth of $\mathrm{p}-1$ internodes.

Our results suggest two modes of action for regulation of $\mathrm{GA}_{3}$-promoted growth in Avena stem segments by kinetin. The first involves an alteration in soluble protein pools. Kinetin significantly increases the pool of soluble proteins over water controls in Avena IM segments. The peak level is reached within 3 hours in the supernatant fractions, whereas with $\mathrm{H}_{2} \mathrm{O}$, it requires 9 hours. There is also a sharp rise in soluble protein in the "wall" fraction in kinetin-treated segments with the maximal level observed at 10 hours. This early rise in protein could possibly mediate kinetin's inhibitory action on $\mathrm{GA}_{3}$-promoted growth. The fact that kinetin maintains high levels of soluble protein longer than $\mathrm{H}_{2} \mathrm{O}$ or $\mathrm{GA}_{3}$ alone, suggests that kinetin affects protein metabolism, either by retarding the breakdown or promoting the synthesis of protein. Recent studies by Shibaoka and Thimann (1970) would favor the idea that kinetin functions to retard protein degradation. Other hormones such as gibberellins, L-thyroxine, and hydrocortisone, have been found to regulate protein turnover (Tompkins 1969, Filner et al. 1969).

One further interpretation here is that kinetin, interacting with $\mathrm{GA}_{3}$, could be acting on the same process, e.g., in cell wall extension. In kinetin-treated segments there is a large increase in soluble protein in the wall. In the $\mathrm{GA}_{3}$ system, wall protein is considerably lower, with the maximum levels occurring 9 hours after the kinetin peak. This suggests that kinetin could be inhibiting the cell wall loosening that is caused by $\mathrm{GA}_{3}$ (Adams, Ph.D. Diss. Univ. Mich. Ann Arbor, 1969).

A second postulated mode of action for kinetin in this system involves carbohydrate metabolism. The effect of kinetin could be to draw off substrates for another synthetic process. This would also limit the substrates needed for the "GA 3 process" which involves an increase in cell wall synthesis (Adams, Ph.D. Diss. Univ. Mich. Ann Arbor, 1969). The evidence for this idea is examined below.

It is evident that sucrose causes a significant increase in longitudinal growth of IM segments in the absence of exogenous kinetin and $\mathrm{GA}_{3}$. Kinetin in the presence of exogenous substrate greatly inhibits sucrose-induced growth (below $\mathrm{H}_{2} \mathrm{O}$ controls). This suggests that kinetin is diverting substrate into a non-growth (perhaps carbohydrate storage and/or wall thickening) type of path- 
way. Furthermore, it was shown that the addition of exogenous substrate to a medium containing $\mathrm{GA}_{3}+$ kinetin only partially relieves the kinetin inhibition of $\mathrm{GA}_{3}-$ promoted growth. These data therefore suggest that kinetin has a significant effect on carbohydrate metabolism. This inhibition could be competitive for substrates but involve both hormones acting at entirely different sites. Such a system suggests a regulatory mechanism by which cells in the IM are able to preferentially utilize substrate. This is based on the assumption that the developing internode has some mechanism for producing cytokinin(s) during the phase of active cell division in the intercalary growth. Letham (1963) has found that the cytokinin activity of apple-fruitlet extracts is greatest during the period of intense cell division and declines markedly about the time of cessation of division.

The results here have shown that kinetin, in regulation of the $\mathrm{GA}_{3}$ growth process in Avena IM segments, markedly affects protein pool size. They also point to a marked effect upon carbohydrate metabolism. Understanding the hormonal interaction of kinetin $+\mathrm{GA}_{3}$ in control of intercalary growth is a necessary undertaking for the understanding of normal cell growth and development. Proof that kinetin is acting in such a fashion must await further studies with DNA, RNA, and protein synthesis inhibitors, and an analysis of key pathways in carbohydrate metabolism to elucidate the primary mechanism of kinetin action in controlling growth and development in Avena internodes.

The authors wish to thank Dr. Hiroshi Ikuma and Mr. Richard Tetley for many helpful suggestions and for their critical reading of the manuscript and Mr. Louis Martonyi for his photographic work. They are also indebted to $\mathrm{Mr}$. J. A. Weber for his valuable help with the study.

This work was supported under auspices of the American Cancer Society Institutional Grant IN-40K.

\section{References}

Brian, P. W. \& Hemming, H. G.: Effect of gibberellic acid and kinetin on growth of pea stems. - Naturwiss. 44: 594. 1957.

De Ropp, R. R.: Kinetin and auxin activity. - Plant Physiol. 31: 253-254. 1956.

Filner, F., Wray, D. \& Varner, J.: Enzyme induction in higher plants. - Science 165: 358-367. 1969.

Fox, J. E. \& Chen, C. M.: Cytokinin incorporation into RNA and its possible role in plant growth. - In Biochem. and Physiology of Plant Growth Substances (ed. F. Wightman and G. Setterfield), pp. 777-789. Runge Press, Ltd., Ottawa, Canada. 1968.

Gorton, B. S., Skinner, C. G. \& Eakin, R. E.: Activity of some 6 (substituted) purines on the development of the moss Tortella caespitosa. - Arch. Biochem. Biophys. 66: 493-496. 1957.

Heide, O.: Non-reversibility of gibberellin-induced inhibition of regeneration in Begonia leaves. - Physiol. Plant. 22: 671-679. 1969.

Kaufman, P. B.: The effects of growth substances on intercalary growth and cellular differentiation in developing internodes of Avena sativa. II. The effects of gibberellic acid. - Physiol. Plant. 18: 703-724. 1965.

- Role of gibberellins in the control of intercalary growth and cellular differentiation in developing Avena internodes. - Ann. N.Y. Acad. Sci. 144: 191-203. 1967.

- Cassell, S. J. \& Adams, P. A.: On nature of intercalary growth and cellular differentiation in internodes of Avena sativa. - Bot. Gaz. 126: 1-13. 1965.

- Ghosheh, N. S. \& Ikuma, H.: Promotion of growth and invertase activity by gibberellic acid in developing Avena internodes. - Plant Physiol. 43: 29-34. 1968.

- Petering, L. B. \& Adams, P. A.: Regulation of growth and cellular differentiation in developing Avena internodes by gibberellic acid and indole-3-acetic acid. - Amer. J. Bot. 56: 918-927. 1969.

Kuraishi, M.: Effects of kinetin analogs on leaf growth. Sci. Papers Coll. Gen. Ed. Univ. Tokyo 7: 67-104. 1959.

Kursanov, E. L.: Combined effects of BAP, GA 3 and IAA on the expansion of isolated pumpkin cotyledons. - Amer. J. Bot. 56: 767-772. 1969.

Letham, D. S.: Regulators of cell division in plant tissues. I. Inhibitors and stimulants of cell division in developing fruits; their properties and activity in relation to the cell division period. - New Zealand J. Bot. 1:336-350. 1963.

Lettré, H. \& Endo, H.: Zur Wirkung von Kinetin und Analogen auf tierische Zellen. - Naturwiss. 43: 84-85. 1956.

Lowry, O. H., Rosebrough, N. J., Farr, A. L. \& Randall, R. J.: Protein measurement with the Folin phenol reagent. J. Biol. Chem. 193: 265-275. 1951.

Miller, C. O.: Naturally-occurring cytokinins. - In Biochem. and Physiology of Plant Growth Substances (ed. F. Wightman and G. Setterfield), pp. 33-47. Runge Press, Ltd., Ottawa, Canada. 1968.

- Skoog, F., Von Saltza, M. H. \& Strong, F. M.: Kinetin, a cell division factor from deoxyribonucleic acid. - J. Amer. Chem. Soc. 77: 1329. 1955.

Murashige, T. \& Skoog, F.: A revised medium for rapid growth and bioassays with tobacco tissue cultures. - Physiol. Plant. 15: 473-497. 1962.

Tompkins, G. N.: Control of specific gene expression in higher organisms. - Science 166: 1474-1480. 1969.

Wittwer, S. H. \& Dedolph, R. R.: Some effects of kinetin on the growth and flowering of intact green plants. - Amer. J. Bot. 50: 330-336. 1963 . 
This document is a scanned copy of a printed document. No warranty is given about the accuracy of the copy. Users should refer to the original published version of the material. 